\title{
A PARADIGM OF REFORMS WITH ALTERNATE ENERGY SOURCES
}

\author{
EISA AL-HADDAD \& MOHAMED RIZWAN \\ Kuwait Oil Company, State of Kuwait.
}

\begin{abstract}
This paper focusses on rapidly growing gas demand in the state, its key drivers and solutions. Emphasis is provided on Kuwait's outlook and ventures into liquefied natural gas (LNG), controls and measures developed for handling constraints in logistical infrastructure. Requirement for tight interaction between the suppliers and consumers was pivotal to segregate different qualities of natural gas to certain consumers. A robust Gas Network system was conceived in the state and it was concluded that under normal operating conditions, it will be possible to supply gas to all essential consumers by combining the available gas from upstream units, refineries and LNG import facility. In this work, a full-blown gas network was simulated to determine transportation capacities, potential restrictions of suppliers and flexibility to use different types of gases available in the system. The study outlined decisive propositions such as the natural gas produced in the state will not be adequate to fulfil the future energy demand, therefore, additional sources such as LNG were more deeply analysed. Moreover, the current energy strategy is primarily based on fossil fuels and hence more efforts were required in implementing renewable energy solutions. In line with this approach, implementation of state sponsored renewable energy projects is underway and by 2030 the share of renewable energy is planned to stretch up to $15 \%$ of overall power demand.

Keywords: Gas, LNG, Power, Kuwait, KOC, Oil, LPG, renewable, solar.
\end{abstract}

\section{INTRODUCTION}

State of Kuwait was the fourth-largest consumer of electricity per capita in 2011. Flourishing economy pushed the demand for power supplies even higher. Harsh weather conditions and subsidized power cost are prime drivers for electricity consumption. In 2017, the electricity consumption exceeded 13,800 MW [1]. Whilst Kuwait can provide itself completely with self-produced energy, the rest of the self-produced energy is either exported into other countries or unused.

Although ongoing projects will help boost Kuwait's generation capacity, it is likely that more will be needed to sustain progress in meeting rising demand. State of Kuwait has also issued a request for expressions of interest for a construction of integrated power plants based on renewable energy.

As part of remit of this study, it was imperative to analyse the coverage of the Essential and Non Essential consumers supplied with two main types of Energy sources of Gas, from MINA AL AHMADI Liquefied Petroleum Gas (LPG) plant (Normal Operation), Dew. Point Depression Unit (DPDU) plant (Emergency Operation) and LGNI (Normal Operation). It was also verified if the Kuwait Gas Network will be capable to transport all the gas injected in the system to supply the Essential and Non Essential Consumers by identifying potential physical restrictions in the transportation of gas and checking the convenience of new projects of pipelines to feed with lean Gas.

\section{FUEL SUPPLY FOR POWER STATIONS}

Power Generating Plants use different types of fossil fuels available in Kuwait such as natural gas, heavy fuel oil, crude oil and gas oil. Kuwait consumes large amounts of fossil fuel to generate electricity for local consumption. By considering other types of alternative or 


\section{Past Trend}

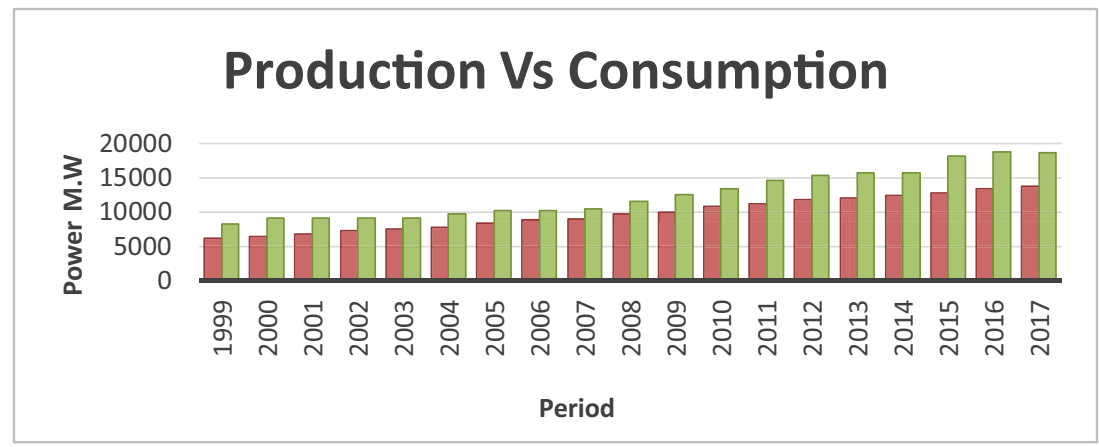

Figure 1: Present demand [1].

\section{Future Forecast}

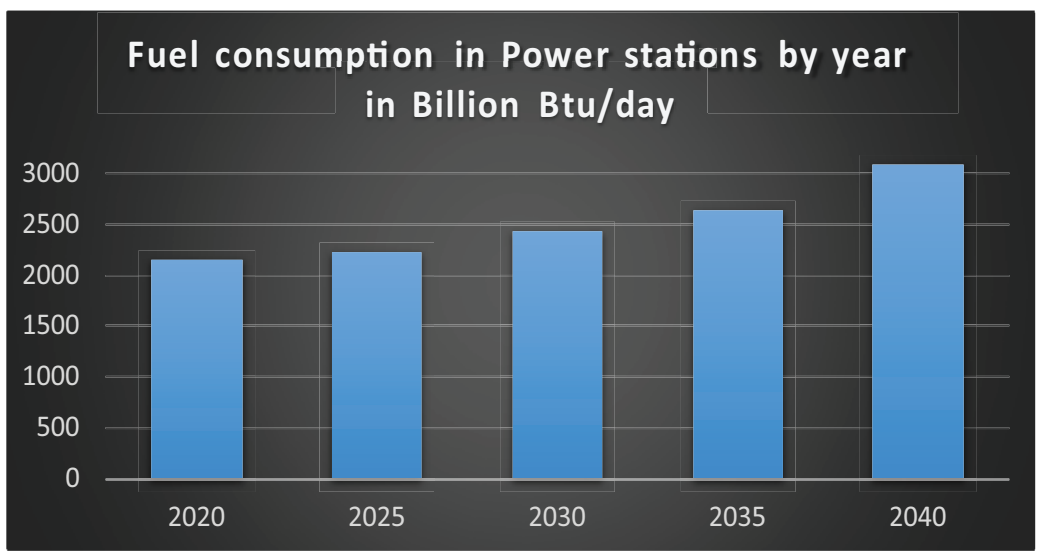

Figure 2: Future demand.

renewable energy for power generation, Kuwait can lower its consumption of fossil fuel and consequently prolong the life of its oil reserves and increase its export quantity. Supply of Natural Gas could play a key role in future developments of the electricity and water production sectors. Plans are to increase drilling for natural gas, and limit flaring of associated gas by upgrading the necessary infrastructure. Figures 1 and 2 explain the present and future demands.

\section{FUEL GAS}

\subsection{Fuel gas in Kuwait}

In order to reduce the consumption of oil for producing electricity, Kuwait is also considering increasing natural gas plants, both domestic and imported, for generating electricity and water desalination. 
The opportunity cost of using oil to generate electricity as compared to selling it in the international market became too high for Kuwait. This has prompted the country to look at other sources for generating electricity, primarily natural gas, as it is fairly simple to use natural gas as in place of oil for generating electricity. However, maintaining a continuous supply of natural gas would be a challenge as Kuwait currently extracts less than the gas demand of power stations.

The best option is to import natural gas, which it does during peak summer season when the demand for electricity is at its all-time high. The country is even planning to increase natural gas imports as it can sell the additional oil in the international market.

Kuwait is currently in talks with various international gas suppliers and is mulling at various options including gas pipelines and liquefied natural gas (LNG). It also plans to increase its natural gas daily production to $4 \mathrm{bn} \mathrm{cu}$. ft. by 2030 . The country has invested $\$ 100$ billion in energy projects over the next five years, which includes plans to build a permanent floating LNG storage and regasification terminal to cope with its rising demand for gas.

\subsection{Dew point depression technology}

Kuwait Oil Company's (KOC) emphasized in opting for technology beyond traditional use, hence built a Dew Point Depression Unit (DPDU), the first-of-its-kind built in Kuwait. The DPDU is a large Butane based refrigeration system to cool the gas to $12^{\circ} \mathrm{C}$. It is known that the lowest temperature of Pipeline at $1 \mathrm{~m}$ depth is $17^{\circ} \mathrm{C}$. Five degree differential ensures no possibility of condensation in the line (see Fig. 3).

\subsection{Need for more gas - Introduction of LNG}

It is a fact that high demand for gas is surpassing current supply. To overcome the current situation a temporary solution was found in floating storage regasification unit (FSRU). LNG import facility (FSRU) was commissioned in 2009.

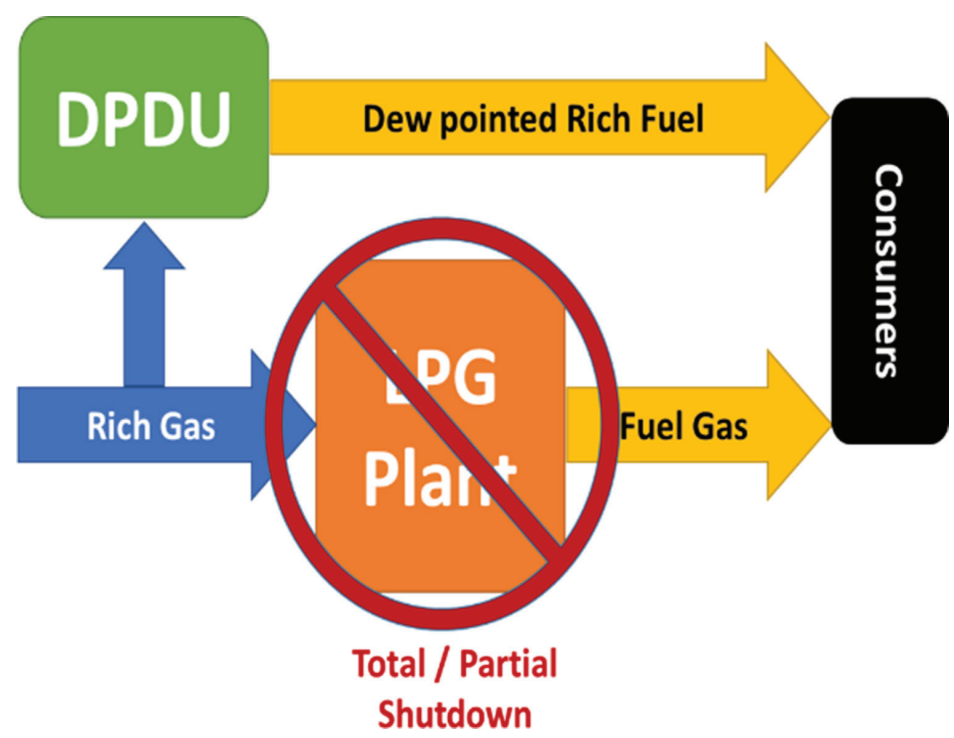

Figure 3: DPDU process graph. 


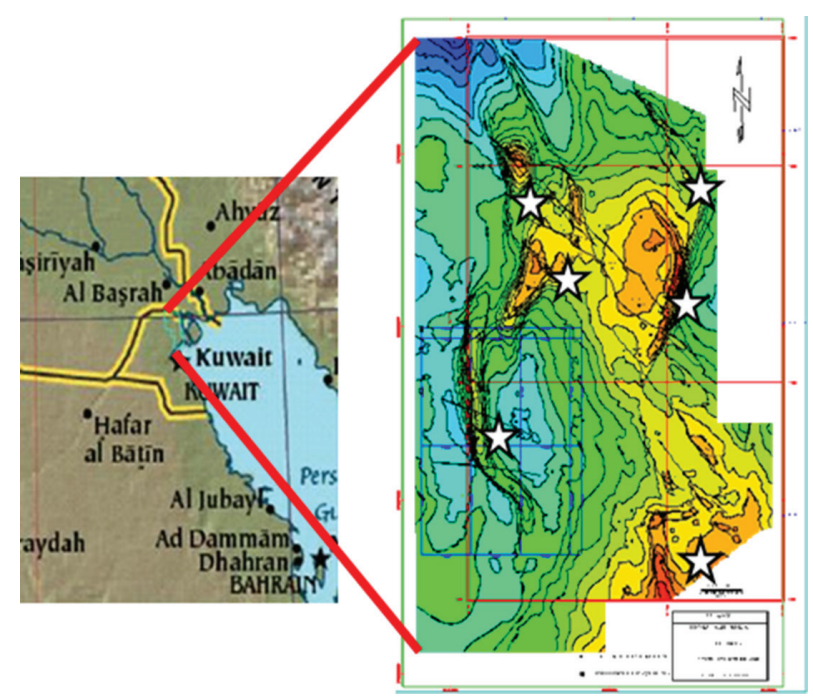

Figure 4: Free gas fields location in Kuwait's map.

The main aim is to secure Kuwait's energy demand by compensating PS gas oil/fuel oil consumption.

Original design capacity of the unit is 500 MMSCFD. The unit consists of import berth and floating regasification ship. The unit originally designed to operate during peak summer seasons only.

Free gas exploration was successful when a free gas production facility (Early Production Facility 50) (EPF-50) 2008 with $~ 180$ MM scf/day production. Furthermore, seven more facilities will be commissioned by 2022 to reach 1B scf/day.

\subsection{Free gas exploration}

Free Gas Exploration was successful when a free Gas production facility (EPF-50) 2008 with $\sim 180 \mathrm{MM}$ scf/day production. Furthermore, seven more facilities will be commissioned by 2022 to reach 1B scf/day (see Fig. 4).

\subsection{New permanent sources - LNG import}

New permanent Source - LNG import facility which is the first commercial size LNG facility in Kuwait is under construction costing $\$ 2.93$ billion. It is expected to be commissioned in September 2020.

This project includes the construction of a re-gasification facility, eight LNG storage tanks with a capacity of $225,000 \mathrm{~m}^{3}$ each, and marine facilities including two marine jetties.

\section{LIMITATIONS AND BOTTLENECKS DUE TO INTRODUCTION OF LNG}

\subsection{Fulfilling consumers requirement}

Considering the different types of gases available in the system and the limitation of heating value of some users, it seems more reasonable in terms of security of supply and commercial 
flexibility to make the users compatible with a wider range of fuel gases instead of limiting that range forced by the consumers. However, this was not possible due to different specifications of power generation turbines.

Special care was taken for density variations and the volumetric flow that is necessary to transport the requested energy flow. The quality of the blended flows of gas, if any, or the non-blended gas must fulfil the requirements of the maximum low heating value. (BTU/SCF) (LHV) for several consumers

As the gas network is working at its physical limits, the integration was focused to avoid transient effect with starting or stopping main consumer that could create operation problems that may affect the stability of the network. This was analysed thoroughly in a detailed study.

\subsection{Network back pressure control}

It was necessary to limit the back pressure to less than 29 barg at an LPG plant.

Enough pressure should be available so as the pressure at Northern Station does not fall below 21 barg. Suction pressure requirements of fuel gas booster compressor (FGBC) at a Booster Station - 180 of KOC (BS-180) is approx. 26.6 barg high pressure stream can join the network and meet the discharge pressure of FGBC at BS-80 (38 barg) when it is running.

As a counter measure pressure set point was determined dynamically depending on the operating scenario. BS-180 will remain undisturbed. Pressure of Al-Zour LNG Import Project (LNGI) gas at Zour tie-in shall be dynamic and maintained above the tie-in pressure control valve (PCV) at BS-180. The scheme is under implementation (see Fig. 5).

\subsection{Fuel gas quality control}

It was necessary to assess network capability to provide MEW with the required fuel gas designated for each power station (different calorific value) in pre-LNGI and post LNGI conditions under different scenarios. In the wake of introduction of LNG, two additional qualities are being introduced, they are:

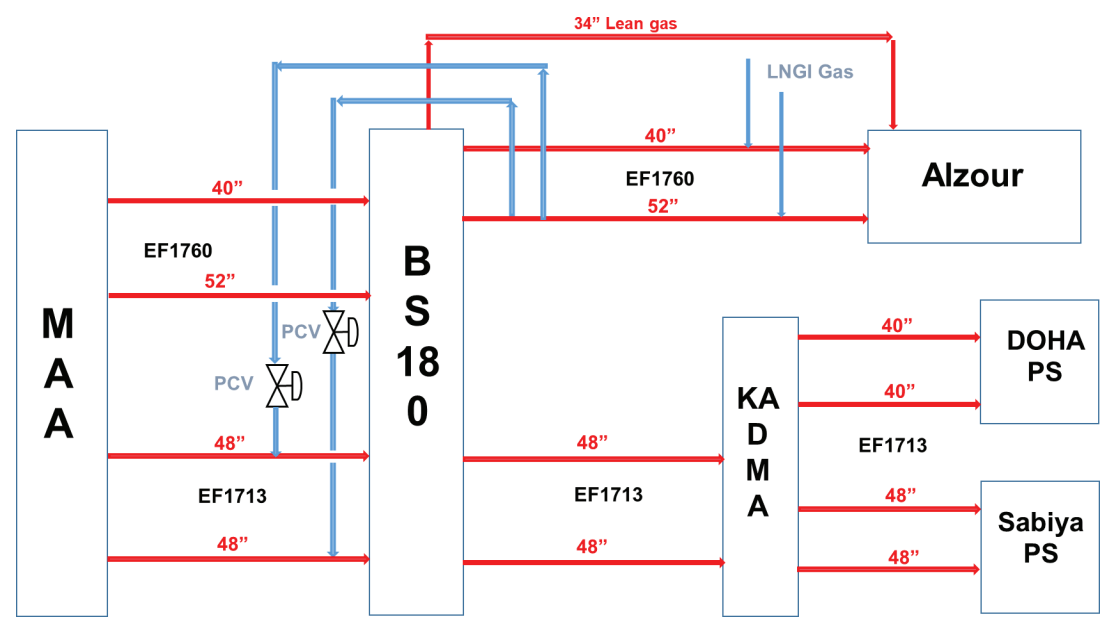

Figure 5: Power stations gas network graph. 


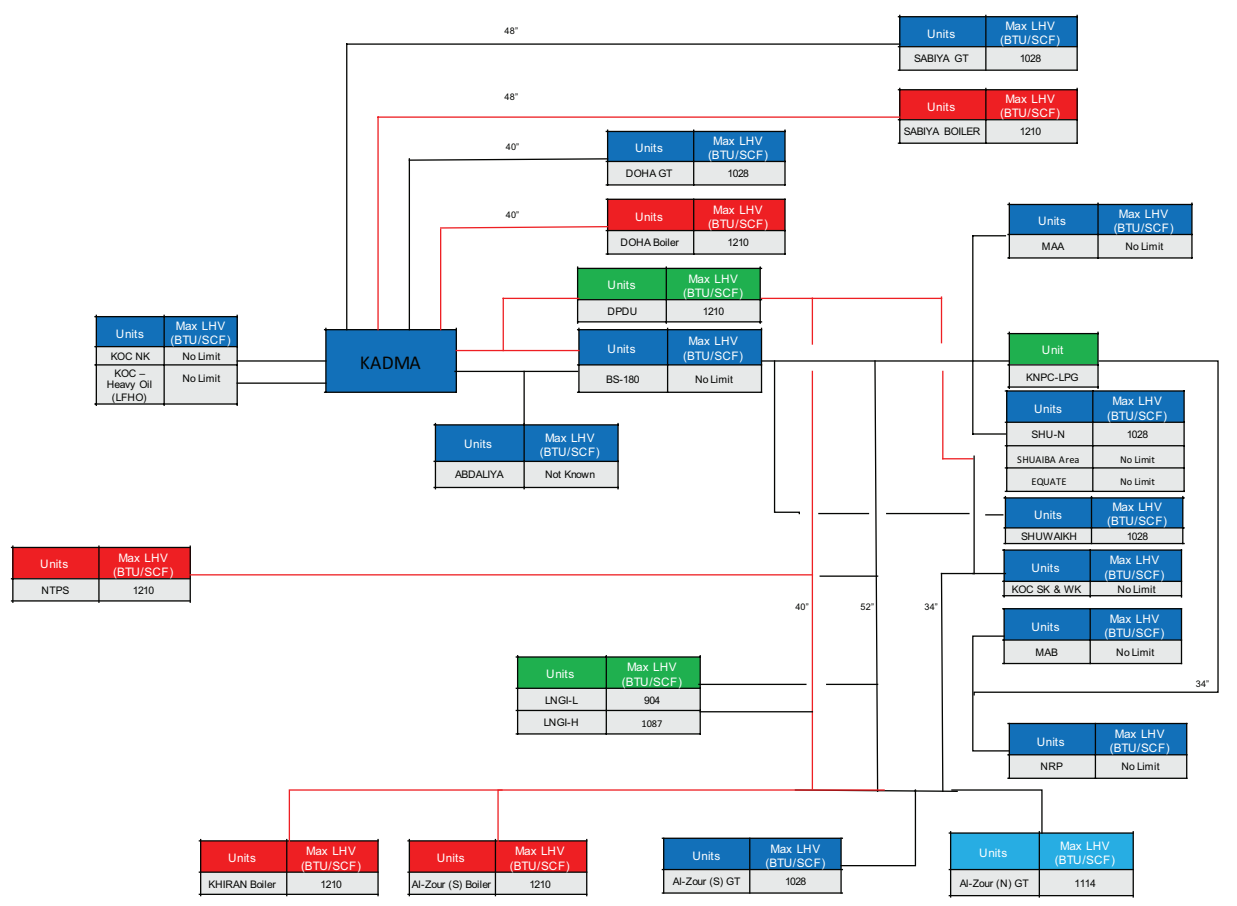

Figure 6: Gas consumer's requirement scheme.

LNGI-light - 904 BTU/SCF

LNGI-heavy - 1087 BTU/SCF

LNGI-heavy needs to be blended with lean FG prior to supplying specific MEW units; the blending strategies proposed are listed in the following section [3, 4].

Max LCV acceptable for existing GTs shall be 1028 BTU/SCF, however, the upper limit for future GTs in power stations will be specified as 1114 BTU/SCF as agreed (see Fig. 6).

\section{RENEWABLE ENERGY}

\section{$5.115 \%$ renewable energy}

In order to minimize the Greenhouse gases emission and to better utilise hydrocarbon produced in Kuwait a vision to cover $15 \%$ of Kuwait's peak load [2] with renewable energy by 2030 was initiated. To complement this vision several initiative were taken by different entities in the country. So far, the projects done are early steps that are hoped to pave the way for larger milestones to come.

\subsection{KOC SEDRA project}

As a first step for the utilization of solar energy technologies in Kuwait's oil sector, SIDRA 500 opening ceremony was in October 2016 with a capacity of 10 megawatts, aiming reducing the environmental emissions and encouraging the green energy, KOC constructed X-ELIO, SIDRAH 500 which considered the first large scale solar power plant in Kuwait oil sector [2]. The name of 


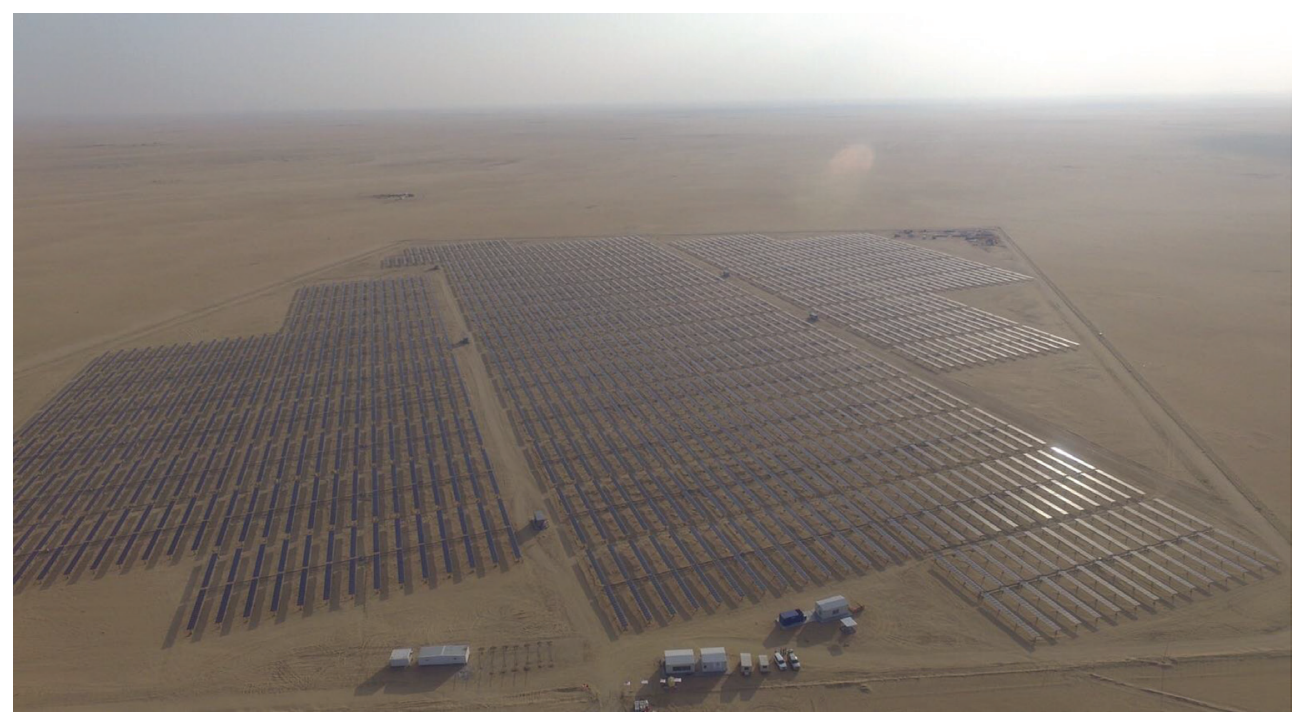

Figure 7: Aerial view of Sedra project. Mina Al Ahmadi

SIDREAH-500 reflecting the environmental benefits of the project. Sidra is a type of tree which widely grown in Kuwait and can bear the severe weather conditions. Since trees has the ability to absorb carbon dioxide $\mathrm{CO}_{2}$ from the atmosphere, SIDRAH 500 project avoids the emission of more than 205,000 tons of $\mathrm{CO}_{2}$ which is equivalent to planting 500,000 Sidrah trees [2].

SIDRAH 500 is connected to the national grid through a KOC owned distribution substation F-193. Solar electricity produced by the plant is not stored. At daytime, the solar plant is working to support the load. At nighttime, the load gets its electricity from the national grid. The electricity produced by SIDRAH 500 powers 29 Electrically Submersible Pumps ( ESP's) in umm-Gudair oilfield in west Kuwait. This reduces KOC electrical power consumption from the national grid. Furthermore, the excess electricity from SIDRAH 500 is exported to the national grid which can supply up to 1000 homes (see Fig. 7).

\subsection{Kuwait institute for scientific research masterplan}

A master plan to make the vision of making $15 \%$ of consumed power supplied by renewable by 2030 a reality is being prepared by Kuwait Institute of Scientific Research (KISR). The plan is considering the area of Shagaya. The targeted installed capacity is 2,500 MW [2] and it is planned to rely on modified Technology mix (Table 1).

Table 1: KISR renewable energy proposed master plan [2].

\begin{tabular}{lll}
\hline Phase 1 & 1. & $50 \mathrm{MW}$ Solar Thermal Power Plant (Under Signature) \\
(70 MW) & 2. & $10 \mathrm{MW}$ Solar Photovoltaic Power Plant (Contract Signed 12 February 2015) \\
& 3. & $10 \mathrm{MW}$ Wind Farm (Contact signed 26-March 2015) \\
& 4. & $35 \mathrm{~km}$ over head Line (Contract Signed) \\
5. & $132 \mathrm{kV}$ Substation (Contact Signed) \\
6. & Infrastructure and Administration Buildings (Bids under review) \\
\hline
\end{tabular}




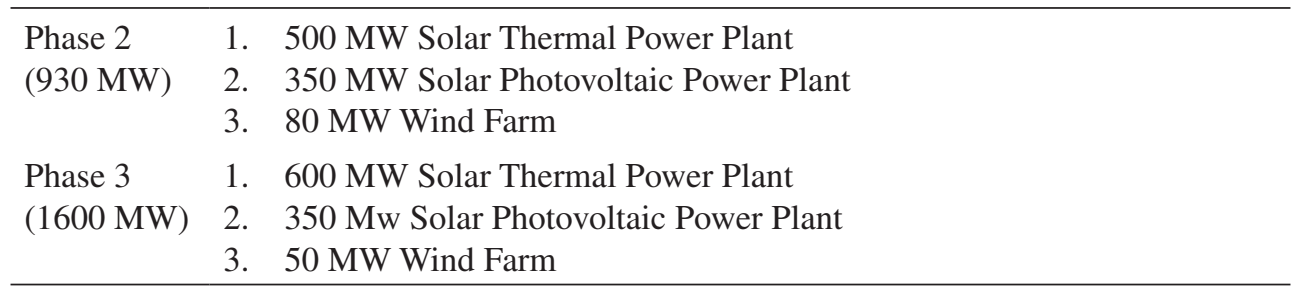

\section{CONCLUSION}

As it will not be possible to cover the complete demand of energy of the essential and the non-essential consumers only using all natural gas produced in the state; it will be recommended that additional sources such as LNG to be more deeply analysed and studied.

Current energy strategy is primarily based on fossil fuels. In order to minimize the greenhouse gases emission and to better utilize hydrocarbon produced in Kuwait, a vision to realize $15 \%$ of Kuwait's peak load [2] with renewable energy by 2030 is on the cards. The State is carrying out ambitious projects related to renewable energy, especially solar and wind power, to reduce dependence on oil for electricity production. Continuing this tradition, leading the nation's efforts to find the renewable energy solutions is most appropriate for the unique climate conditions of Kuwait.

\section{ACKNOWLEDGEMENTS}

The author would like to thank the management of KPC, KOC and KIPIC for the valuable guidance and information provided. Credits are also given to KISR for their pioneering research in concentrated solar thermal technologies as well as photovoltaic panels.

\section{REFERENCES}

[1] Electrical energy 2018, Statistical Dept. \& Information Centre at the Ministry of Electricity \& Water State of Kuwait, 2018.

[2] Conference: Dr. Raed Sherif, Solar Project Opportunities in Kuwait Oil Company. MENASOL, 2016.

[3] Segers, M., Cannon, P., Binkowski, B., Sanchez, R., Gutierrez, C. \& Hailey, D., Blending fuel gas to optimize use of off-spec natural gas. In ISA Power Industry Division 54th Annual I\&C Symposium.

[4] Guidebook to Gas Interchangeability and Gas Quality, British Petroleum 2011. 